\title{
The Compensation Payment Form and Art of Elderly Human Resources in Small And Medium-Sized Energy Enterprises
}

\author{
Ke-ying Chen ${ }^{1, a}$, Ti-sheng $\mathrm{Hou}^{2, \mathrm{~b}}$, Tian-pei Chen ${ }^{3, \mathrm{c}}$, Dong-qiang Wang ${ }^{3, \mathrm{~d}^{*}}$ \\ 1School of Business Administration, South China University of Technology, 510641, Guangzhou, \\ China \\ 2. Jiangsu Huaya Chemical Fiber Co., Ltd.China, 214253, Jiangsu, China \\ 3.Tourism College, Chongqing University of Arts and Sciences, 402160, Chongqing, \\ China \\ aketizu6002@163.com, bwdqtsq@126.com, email 1250508192@qq.com dcqwdq2011@163.com
}

Keywords: Compensation payment; SMEES; Elderly human resources; Menu compensation; Balancing urban and rural development

\begin{abstract}
Small and medium-sized energy enterprises must focus on the utility of payment and incentive process to satisfy the physiological needs and psychological demands of elderly human resources. From this sense, The menu compensation is good choice to improve payment satisfaction of elderly human resources, which needs to widen the selection range of compensation, perfect salary payment mechanism and establish compensation feedback mechanism. Meanwhile, small and medium-sized energy enterprises must focus on the characteristics of elderly human resources, payment culture tradition of the organization and take adaptive strategies according to the people, job, opportunity and scene.
\end{abstract}

\section{Introduction}

Elderly human resources not only take on general characteristics of human resources including value-added, regeneration and periodicity, but also own rich knowledge and technical skills, wide network resources, profound human capital potential and strong career choice autonomy, with the continuous extension of life expectancy at the same time, which play an irreplaceable role in the economic and social development. Therefore, at present, a lot of small and medium-sized energy enterprises gradually began to attach importance to on-the-job and retired elderly human resource development and human resource management work, which not only give impetus to develop older human resources potential effectively, but also promote the sustainable development of small and medium-sized energy enterprises in some key areas. But in contrary to the middle-aged and young human resources, there are many aspects of the particularity for elderly human resources. Because of lacking more perfect compensation laws and regulations at the same time, the compensation payment problem has been bothering small and medium-sized enterprise human resources managers.

\footnotetext{
${ }^{*}$ Corresponding author. Tel.: +86-13650536605; fax: +86-23-49685276.

E-mail address: cqwdq2011@163.com (DQ. WANG).
} 


\section{The Innovation of Compensation Payment Forms of Elderly Human Resources in Small And Medium-Sized Enterprise-—Menu Compensation}

Expectations theory in human resources management suggests that payment satisfaction factors mainly include three aspects: namely, the fairness of compen payment number, payment process, the realization of individual utility maximization.Obviously, for the elderly human resource, because their sensitivity to the payment is much less than the young people in this age, so payment quantity affect sexual problems is relatively small.From this sense, Small and medium-sized energy enterprises must focus on the utility of payment and incentive process to satisfy the physiological needs and psychological demands of elderly human resources.

The connotation of the menu compensation. As mentioned above, in old age, the elderly human resource in small and medium-sized energy enterprises reduced sensitivity to payment bonuses, etc, and more concerned about their respected degree, the level of health care, life and learning quality.Therefore, the menu compensation just meet the reality of the situation.Menu compensation is that the human resources managers of the small and medium-sized enterprise are prior to take a fixed salary, bonuses, allowances and subsidies, welfare and other forms of compensation into a list or synthesize different compensation project team into different packages according to of elderly human resource physiological needs and psychological demands,just like payment plan, so that such as order in the restaurant as well as for self-service,the elderly human resources can choose a way to payment according to expectation .Menu compensation pays attention to wether payment can meet the needs of individual utility maximization or not, gives full consideration to the physiological characteristics of the eldely human resources, career stability, psychological characteristics and salary expectations, which can better meet the needs of elderly human resources.

The menu compensation operation. For the specific operation of the menu compensation, whether single or combined compensation packages, we not only focus the utility maximization of payment of the elderly human resource, but also focus the process of payment incentive.To improve menu compensation operation effectiveness, we must focus on the content and process of incentives, the purpose of that is to let the elderly human resource gain compensation in the process of payment and feel the material satisfaction and psychological comfort.

Firstly, broaden the payment choice range to ensure the fairness of the compensation system.Based on the diverse welfare needs of elderly human resources, the menu compensation should broaden the possible choice of compensation.This should include at least work supplies subsidies, health advice, psychological problems, fitness sports, tourism at home and abroad, the elderly special insurance, the training of learning content, so that elderly human resources can be free to choose according to need.Secondly, perfect compensation mechanism.compen commissioner should pay full attention to the respect of elderly human resources demand, not only to treat them just as the young and middle-aged human resources equally, but also to improve their status and role in the organization and highlight the the value of elderly human resources and improve the customization diversity, flexibility and self-service mechanism of payment, change "Payment to stay" to "leave a person at heart".Thirdly, establish compensation feedback mechanism.we should listen to the opinions of the elderly human resource to payment regularly and arrange special salary specialist to solve their compensation issues, encourage the old human resources to participate in the development of the payment system and make sure absolute perfection in the future work payment adjustment. 


\section{Rich Compensation Payment Arts of Elderly Human Resources in Small And Medium-Sized Enterprise- - Adaptive Strategies}

JasWan McAdams in the book of "the advantage of the incentive plan" points out, " only the best principle, and no best practice".Obviously, the compensation payment is exquisite art and must not be formulaic. The empirical study of Gu Jianping (2005) also shows that higher levels of positive correlation exists between knowledge workers' payment process and the degree of motivation. Compensation payment environment, payment form and payment time are relatively large on the degree of incentive of knowledge workers.This shows that small and medium-sized energy enterprises must focus on the characteristics of elderly human resources, payment culture tradition of the organization and and take adaptive strategies according to the people, job, opportunity and scene to rich small and medium energy enterprises payment art of elderly human resources.

Adopt diversified measures in line with appropriate person. Different elderly human resources' preferences(such as age, gender, temperament, personality, education degree, skill levels )in the form of compensation payment are not the same.for example, younger workers are chasing wage bonus, challenging tasks, promotion of demand, in contrast,elderly human resources hope to have generous pension and medical insurance.Therefore, firstly,small and medium-sized energy enterprises should design good payment questionnaire, survey and grasp aged physiology, psychology and other aspects of human resources demand comprehensively to make sure the things they want according to the elderly human resources endowment health care demands, then adopt diversified measures to select the appropriate compensation payment in line with appropriate person.Secondly,we should adopt and develop the flexible salary and welfare system, such as free parking, free meals, health care, pensions, health benefits, etc., meet the different needs of old age.Moreover, compensation specialist should make comprehensive understanding of the real demands of elderly human resources and communicate with the elderly human resource efficiently and constantly adjust compensation payment.

Adopt diversified measures in line with appropriate job. The position nature, task difficulty and labor level in small and medium-sized energy enterprises are different,so it is necessary to adopt diversified measures in line with appropriate job for the elderly human resources payment in small and medium-sized energy enterprises (MSES).For special jobs, you can take the following ways: for task-based jobs, according to the characteristics of the elderly human resource's body and mind, small and medium-sized energy enterprises can give elastic off welfare in the process of payment and arrange the prescribed time to complete their tasks, who can choose flexible working hours, vacation arrangement,and even decide the working place in the office or other places.For management jobs, small and medium-sized energy enterprises can pay compensation payment attention to long-term incentives in the process of payment and carryout different ways through the stock option, annual bonus, profit sharing, profit sharing, stock appreciation to recognize and to ensure management contribution and long-term interests of elderly human resources.For technical jobs, small and medium-sized energy enterprises can give them more autonomy, allow them to learn by job sharing, job rotation, training form to obtain the intrinsic rewards, and give compassionate welfare for their title promotion, evaluation of outstanding and advanced involved in in the process of payment.

Adopt diversified measures in line with appropriate opportunity. The small and medium-sized energy enterprises (SMES) should choose different compensation payment opportunity for older human resources according to their family needs, psychological demands.Firstly, for elderly workers 
families need, we can choose payment object - partner.In traditional Chinese culture, the "home" culture in payment art plays an incentive and condense the role of human resource of the elderly.Japanese McDonald's burger(the President of rattan tiantian) know how to help employees shape "great" women to make their employees to be a successful man.This case shows that we can choose year-mid, the year-end, even older workers spouse birthday as appropriate opportunity to pay a certain amount of compensation to their spouses to win the trust and support of family members in the process of payment of elderly human resource in small and medium energy enterprises.Secondly, to meet the elderly' psychological need, we can choose the appropriate payment opportunity to special needs. Traditional timing compensation form, such as payment by year, week and hourly, etc can not meet the special requirements for elderly human resource and it is adverse to incentive the enthusiasm of elderly human resource.Therefore, in view of personality needs of the elderly human resource in the birthday celebration, sons and daughters to marry, illness in hospital, family misfortune,we can launch diversified compensation payment method and pattern to meet elderly human resource emotional satisfaction and then receive the unexpected effect.

Adopt diversified measures in line with appropriate scene. Human resources in different career development stage show different psychological tendency, and the elderly in the late stages of career development, more focused on career stability, accordingly respected desire is more intense, due to the attitude stability. The appeal is more apparent in the strength of the Chinese "face" culture.Therefore in the process of compensation payment, the first is to hold a compensation commendation conference regularly. The elderly who get high salary can introduce their feelings and expectations about the future, and they can gain self-esteem and the respect for the needs of others in the process, and further inspire confidence and potential of the elderly human resources.Of course because of the sustainability of incentive effect of elderlyhuman resources, the frequency can be reduced.The second is to create good environment for compensation payment.In order to meet the respect demand of elderly human resources, based on the principle of grand and warm, we can the elderly who get high compensation payment to realize the solidarity and enhance a sense of pride through the propaganda window, portals, internal way, such as newspaper, banner, commemorative propaganda.

\section{Conclusion}

In contrast to traditional salary payment, whether it is a limited piece and piece, a progressive piece and piece, cut piece and work piece, or excess individual piece and collective piece of piecework, compensation forms are not suitable for the number of elderly human resources who lose interest in production of qualified products or complete more work, even this way may cause elderly human resource working strain, stress, hazardous to health. For new forms of floating rate and fixed compensation, it is based on the premise and basis to improve enterprise management level and staff being eager to get more salary, which can't reflect the compensation value of the elderly human resources demands. Therefore,to reflect the economic interests and the partner status safeguard of elderly human resources, the employer must be innovative in perfecting payment form and riching payment art to improve compensation satisfaction of elderly human resource in the small and medium-sized energy enterprises according to the people, job, opportunity and scene. 


\section{Acknowledgements}

The article is sponsored by the annual research project of humanities and social science of ministry of education (number: 12YJCZH044;the head of the project: Feng Hai-fang)

\section{References}

[1]X.P. Jiang Compensation management (Sichuan university press, China,2007). [In Chinese].

[2] Y.P. Jin. Compensation management (Northeast university of finance and economics press, China,2008). [In Chinese].

[3] Scott Maynard.The application of logistic regression analysis(Gezhi publishing house, USA,2012)

[4] Y.Q. Yao.Human Resources Development (Renmin University of China, China, 2011 )[in Chinese].

[5] J.Y.Yang, R.M. Wu. Economic and social development, (2003) No.6, p.35-39. [In Chinese].

[6] S.Q.Tian, D.Q Wang.Energy Education Science and Technology, PART A :Energy Science and Research, Vol32,(2013) No.1, p.231-234.

[7]Y.P.Gu.. Journal of finance and trade research, (2005) No.2, p.25.[In Chinese].

[8] Compensation Payment Arts on http:// www.jobcn.com

[9] Six Principle of Compensation Payment on http://blog.ifeng.com/article

[10]Three Forms of Compensation Payment on http://news.cnal.com/management 